\title{
Pulmonary nocardiosis associated with Cushing's disease: a case report
}

\author{
Charalampos C. Mylonas ${ }^{1}$, Georgia Gomatou ${ }^{1}$, Athina Asimakopoulou ${ }^{1}$, Christos Masaoutis ${ }^{2}$, \\ George Kyriakopoulos $^{2}$, Maria Kopelia' ${ }^{1}$, Konstantinos Syrigos ${ }^{1}$, Garyphallia Poulakou ${ }^{1}$ \\ ${ }^{1}$ Third Department of Medicine, Sotiria General Hospital for Chest Diseases, National and Kapodistrian University of \\ Athens; ${ }^{2}$ Department of Pathology, Evangelismos Hospital, Athens, Greece
}

\begin{abstract}
Nocardia spp. is a genus of Gram-positive bacteria which can cause cutaneous, pleuropulmonary, or disseminated disease. The latter two forms are encountered in immunocompromised patients, with prolonged usage of corticosteroids being a wellrecognized risk factor. However, endogenous Cushing's syndrome is less frequently associated with nocardiosis. We report on a 40-year-old woman who presented for further workup of abnormal findings in the chest computed tomography (three lung nodules, one of which being cavitary). She underwent trans-thoracic fine-needle lung aspiration of the cavitary nodule, which led to the diagnosis of lung nocardiosis. Moreover, the identification of cushingoid features from the history and clinical examination initiated further investigation with hormonal laboratory assessment and bilateral inferior petrosal sinus sampling which established the diagnosis of pituitary adrenocorticotropic hormone (ACTH) hypersecretion (Cushing's disease). We conclude that pulmonary nocardiosis can be an opportunistic infection as well as a presenting manifestation of Cushing's disease.
\end{abstract}

Correspondence: Georgia Gomatou, $3^{\text {rd }}$ Department of Medicine, Sotiria General Hospital, Messogion Ave. 152, Athens 11527, Greece. Tel. +30.210 .7763332 - Fax: +30.210 .7778838 .

E-mail: georgia.gomatou@gmail.com

Key words: Nocardia spp.; Cushing's syndrome; pituitary adenoma; opportunistic infection.

Contributions: All the authors contributed equally to this work.

Conflict of interest: The authors report no conflict of interest.

Received for publication: 16 July 2019.

Accepted for publication: 6 October 2019.

${ }^{\circ}$ Copyright: the Author(s), 2019

Licensee PAGEPress, Italy

Monaldi Archives for Chest Disease 2019; 89:1130

doi: 10.4081/monaldi.2019.1130

This article is distributed under the terms of the Creative Commons Attribution Noncommercial License (by-nc 4.0) which permits any noncommercial use, distribution, and reproduction in any medium, provided the original author(s) and source are credited.

\section{Introduction}

Members of the genus Nocardia are Gram-positive aerobic bacteria ubiquitous in the soil, decaying material and environmental fresh or salt water. They mainly act as an opportunistic pathogen in patients with immunosuppression, notably in conditions with impaired cell-mediated immunity, including human immunodeficiency virus infection, solid-organ or hematopoietic stem cell transplants and patients receiving prolonged treatment with corticosteroids [1]. Pulmonary nocardiosis is the most common clinical presentation of infection [2]. Its clinical manifestations include fever and cough as well as dyspnoea, weight loss and chest pain. Nodules/masses and consolidations are the most frequent radiological abnormalities and they might be associated with cavitation [3]. Disseminated disease most commonly results from hematogenous spread of a pulmonary lesion, or less frequently, from a skin nodule. Its prognosis is rather unfavourable, with reported fatality rates ranging from 10 to $50 \%$ in different patient series $[4,5]$.

\section{Case Report}

A 40-year-old woman was referred to our hospital in November 2018 for further investigation of abnormal radiologic findings in a chest computed tomography (bilateral lung nodules one of which cavitated). The patient was an ex-smoker and she had a history of arterial hypertension diagnosed two years ago, dyslipidaemia and depression. She also reported amenorrhea for the last two months and facial hirsutism.

One month prior to the referral, the patient was admitted in a regional hospital for fever and chest pain. Apart from other examinations, a chest CT was performed, which demonstrated multiple infiltrates bilaterally, and ground glass opacities in the left upper lobe. She was treated with broad-spectrum antibiotics. In addition, during her stay in the hospital, she was newly diagnosed with diabetes mellitus. Also, she was diagnosed with persistent hypokalaemia with increased 24-hour urine potassium, while her arterial hypertension was poorly controlled. Thus, suspicion of secondary arterial hypertension was raised and further investigation was performed; blood creatinine $(0.5 \mathrm{mg} / \mathrm{dL})$, urinalysis (within normal limits, except for glycosuria), renal artery ultrasound (normal findings), renin $(0.090 \mathrm{ng} / \mathrm{ml}$, normal range 0.5-1.9 $\mathrm{ng} / \mathrm{ml})$ and aldosterone levels $(92.2 \mathrm{pg} / \mathrm{ml}$, normal range 10 $160 \mathrm{pg} / \mathrm{ml}$ ). Chest symptoms abided with treatment and the patient was discharged from the regional hospital with a prescription of oral potassium supplements. She was advised to complete the work-up as outpatient with a repeated renin and aldosterone test as 
well as morning cortisol measurement and a brain magnetic resonance imaging scan. The brain MRI (without pituitary protocol) did not reveal abnormal findings.

After her discharge, the patient had worsening fatigue, proximal muscle weakness and leg cramps, so ten days later she visited the emergency department of a tertiary hospital of Athens. The biochemical tests revealed hypokalaemia despite oral supplementation. A second chest CT was ordered, which revealed one nodule in the left upper lobe and two nodules in the right middle lobe, one of which cavitated (Figure 1). An abdominal CT was also performed, which demonstrated bilateral adrenal hypertrophy. The patient was transferred to our hospital which is a referral center for chest diseases, for further investigation.

At the time of the admission the patient was haemodynamically stable and she had $\mathrm{SaO}_{2}=92 \%\left(\mathrm{FiO}_{2}=21 \%\right)$. On physical examination she presented a moon face with facial hirsutism, central obesity and proximal muscle weakness. Complete blood count revealed: white blood cells $=15,820$ ( $85 \%$ neutrophils), haematocrit $=41.3$, platelets $=209,700$ and biochemical tests: urea $=24$ $\mathrm{mg} / \mathrm{dl}(10-50)$, creatinine $=0.5 \mathrm{mg} / \mathrm{dl}, \mathrm{K}=3.0 \mathrm{mmol} / \mathrm{L}$ (3.5-5.0), $\mathrm{Na}=146 \mathrm{mmol} / \mathrm{L}(136-145)$, C-reactive protein $=0.45 \mathrm{mg} / \mathrm{dl}(<0.70)$, brain natriuretic peptide $=113 \mathrm{pg} / \mathrm{ml}$ (1-100). Mantoux test was performed $(0 \mathrm{~mm})$ and QuantiFERON test was negative.

The patient initially underwent bronchoscopy; no endobronchial lesions were evident and broncho-alveolar lavage (BAL) and brushing was obtained from the right lower lobe. BAL fluid cytology examination reported rare inflammatory cells. Cultures for aerobes, anaerobes, Nocardia, fungi and Mycobacterium tuberculosis from BAL, brushing and washing were all negative. Aspergillus antigen from BAL fluid was also negative. Therefore, a percutaneous fine-needle-aspiration was performed from the cavitated nodule of the right middle lobe. Cytologic examination was negative for malignancy, but the culture revealed Nocardia spp. Thus, the diagnosis of pulmonary nocardiosis was established and the patient was treated with co-trimoxazole based on the antibiogram sensitivity of the organism (Table 1).

In addition, the patient was investigated for possible endogenous hypercortisolaemia due to compatible history, clinical and laboratory findings (proximal muscle weakness, amenorrhea, hirsutism, moon face, central obesity, new-onset of diabetes mellitus and worsening of hypertension with persistent hypokalaemia). Levels of morning cortisol before and after overnight suppression with $1 \mathrm{mg}$ of dexamethasone were 61.5 and $60.42 \mu \mathrm{gr} / \mathrm{dl}$, respectively (normal range $<1.8 \mu \mathrm{gr} / \mathrm{dl}$ ), which confirmed the diagnosis of endogenous hypercortisolaemia. The levels of ACTH were $126.9 \mathrm{pg} / \mathrm{ml}$ (normal range $5-27 \mathrm{pg} / \mathrm{ml}$ ), thus confirming the ACTH-dependent nature of the hypercortisolaemia. Moreover, the patient was scheduled for further workup with an inferior petrosal sinus sampling in a specialized unit, which established the diagnosis of pituitary ACTH hypersecretion. Finally, transsphenoidal pituitary surgery was performed, and the histologic findings were consistent with an ACTH-secreting pituitary adenoma (Figure 2).

\section{Discussion}

The association of nocardiosis with immunosuppression, especially with reduced cell-mediated immunity, is well-known [6]. In fact, long-term usage of steroids has been reported as one of the major risk factors for pulmonary nocardiosis [7]. Elevated cortisol levels, as those which occur in prolonged therapy with steroids, lead to an impaired immune response by neutrophils and macrophages and diminished recruitment of these inflammatory cells into the infected site [8].

Contrary to exogenous, the endogenous Cushing's syndrome is less frequently associated with Nocardia spp. infections. Endogenous Cushing's syndrome is divided in ACTH-independent
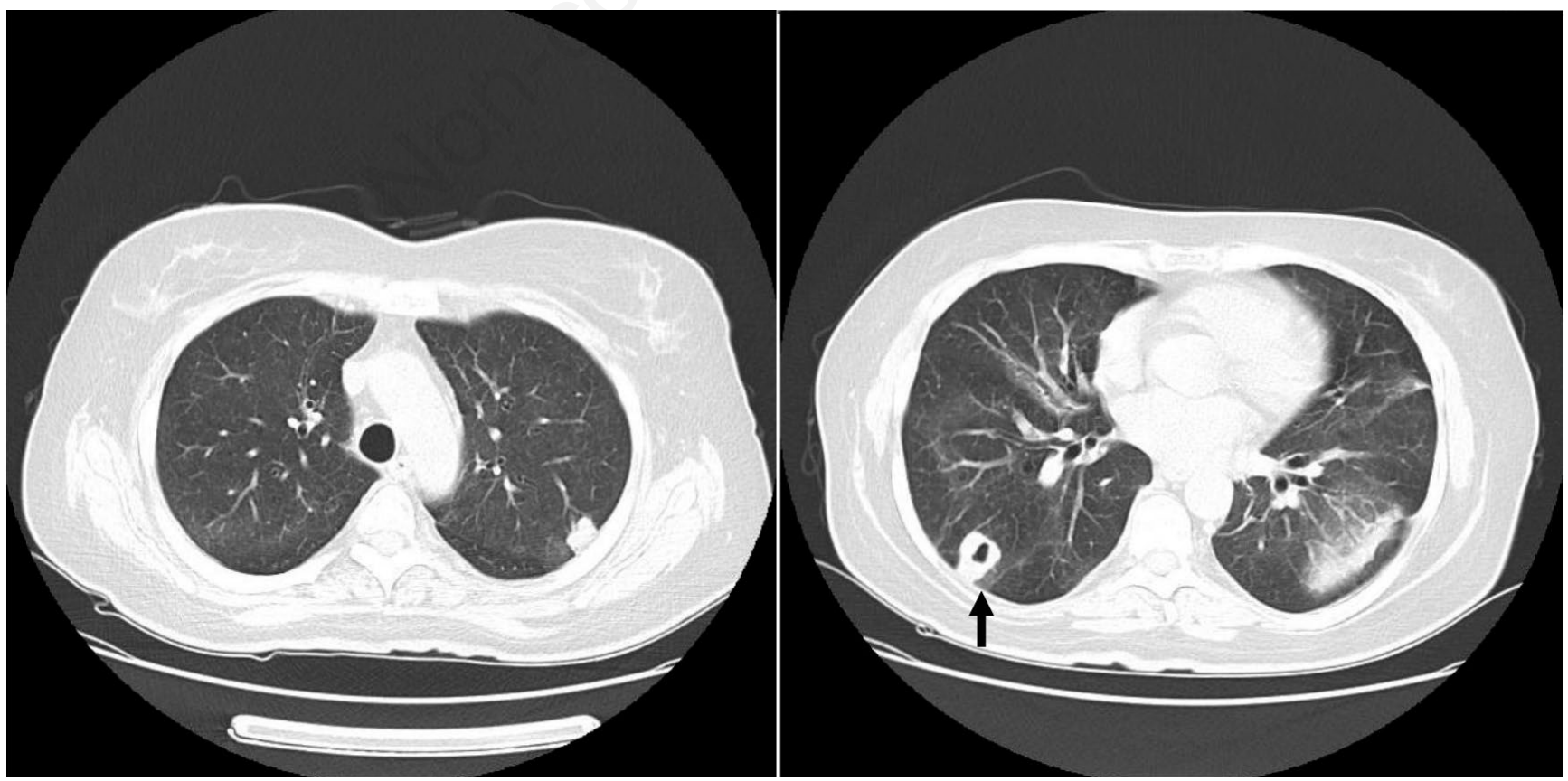

Figure 1. Chest computed tomography. Bilateral lung nodules, one of which with cavitation (black arrow). 
and ACTH-dependent, the latter being further divided in pituitary ACTH hypersecretion in the case of pituitary adenoma (Cushing's disease) and ectopic Cushing's syndrome in the case of ACTHsecreting tumours [9]. A series of case reports have been published describing Nocardia spp. infections in patients with ectopic Cushing's syndrome [10-13]. Even though Cushing's disease is more prevalent than ectopic Cushing's syndrome, there are fewer reports of opportunistic infections occurring in patients with pituitary hypersecretion of ACTH. It has been suggested that higher levels of ACTH (and subsequently, cortisol), as reported in cases of ectopic production of the hormone, are implicated in the higher risk for opportunistic infections [10]. To our knowledge, this is the second case-report describing a case of pulmonary nocardiosis in the setting of pituitary ACTH-dependent Cushing's syndrome [14].

In our case, the patient initially presented with non-specific symptoms of respiratory tract infection, on top of gradually compiled cushingoid features. We presume that the cause of respiratory tract infection during the first hospitalization might have been Nocardia spp., since pulmonary nocardiosis exhibits a tendency towards recurrences, especially with only a brief course of antibiotics, as in this case. It is worth mentioning that patients with nocardiosis generally need 6 to 12 months of antibiotic therapy, depending on their immunological status and the organs infected [6]. The diagnosis of nocardiosis in our case was delayed, which is in line with the data available in the literature, since clinical and radiologic manifestations of pulmonary nocardiosis are non-specific, and diagnosis requires isolation of Nocardia spp. from respiratory samples. In fact, in our case, isolation of Nocardia spp. required a percutaneous lung aspiration from the cavitated lung nodule, while sputum, lung washing and BAL cultures were negative.

Table 1. Antibiotic sensitivities of Nocardia spp. isolated from the fine-needle-aspiration sample.

\begin{tabular}{|c|c|c|c|c|c|}
\hline \multirow[t]{2}{*}{ Antibiotic } & \multirow[t]{2}{*}{ MIC ( $\mu g / m l)$} & \multicolumn{3}{|c|}{ Sensitivity limits } & \multirow[t]{2}{*}{ Interpretation } \\
\hline & & S & I & $\mathbf{R}$ & \\
\hline Amikacin & $\leq 1$ & $\leq 8$ & - & $\geq 16$ & S \\
\hline Amoxicillin-clavulanic acid (2:1) & $\geq 32$ & $\leq 8 / 4$ & $16 / 8$ & $\geq 32 / 16$ & $\mathrm{R}$ \\
\hline Ceftriaxone & $\leq 4$ & $\leq 8$ & $16-32$ & $\geq 64$ & S \\
\hline Ciprofloxacin & $>4$ & $\leq 1$ & 2 & $\geq 4$ & $\mathrm{R}$ \\
\hline Clarithromycin & $>16$ & $\leq 2$ & 4 & $\geq 8$ & $\mathrm{R}$ \\
\hline Imipenem & $>64$ & $\leq 4$ & 8 & $\geq 16$ & $\mathrm{R}$ \\
\hline Linezolid & $\leq 1$ & $\leq 8$ & & & S \\
\hline Minocycline & $>8$ & $\leq 1$ & $2-4$ & $\geq 8$ & $\mathrm{R}$ \\
\hline Moxifloxacin & $>8$ & $\leq 1$ & 2 & $\geq 4$ & $\mathrm{R}$ \\
\hline SXT (Trimethoprim/sulfamethoxazole) & $\leq 0.25 / 4.75$ & $2 / 38$ & - & $4 / 76$ & S \\
\hline Tobramycin & $\leq 1$ & $\leq 8$ & 16 & $\geq 32$ & S \\
\hline Cefepime & 16 & $\leq 8$ & 16 & $\geq 32$ & I \\
\hline Doxycycline & $\leq 1$ & $\leq 1$ & $2-4$ & $\geq 8$ & S \\
\hline
\end{tabular}

S, susceptible; I, intermediate; $R$, resistant.
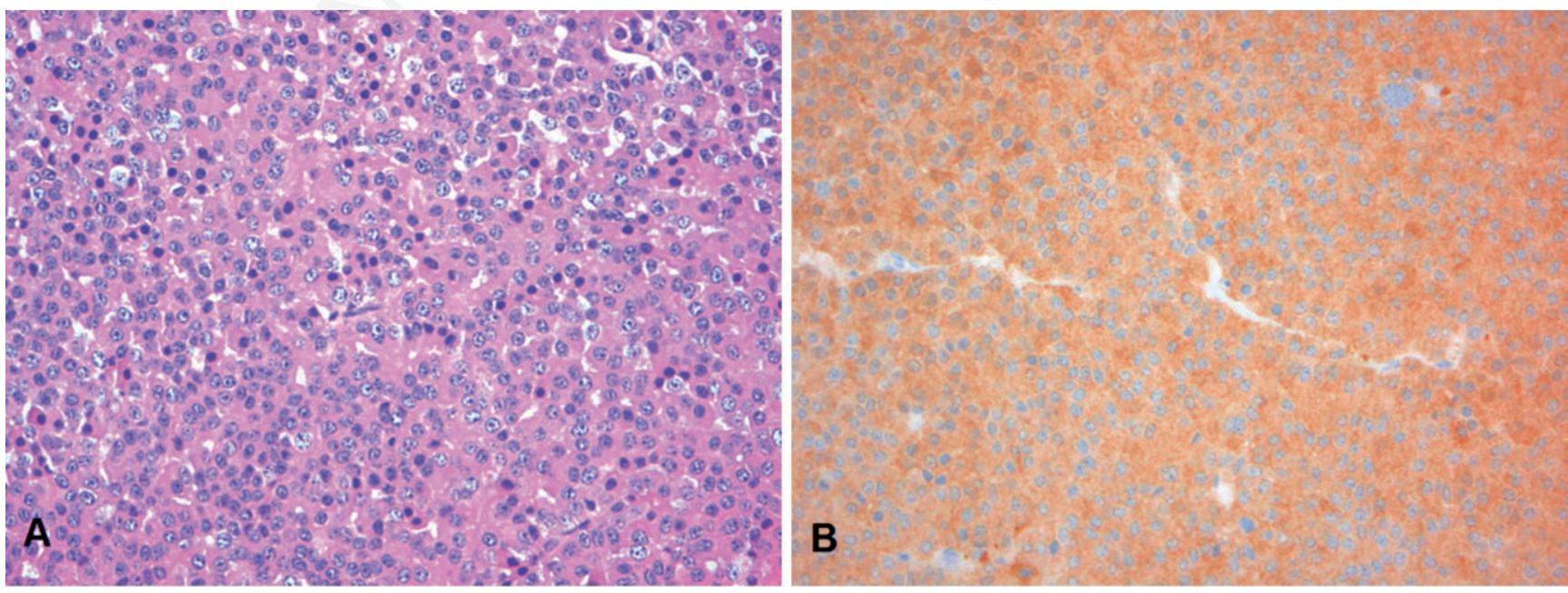

Figure 2. Histology (400x). A) Haematoxylin and eosin stain showing monomorphous cells without acinar architecture. B) Immunohistochemical staining positive for ACTH. 
When the diagnosis of Cushing's syndrome was established in the patient, it was evident that this was the underlying predisposing factor for nocardiosis. Given the existing literature linking pulmonary nocardiosis in endogenous hypercortisolaemia with ectopic ACTH hypersecretion, the radiologic finding of multiple lung nodules in our patient pointed towards a diagnosis of a possible ACTH-secreting tumour. Moreover, the rapid onset of Cushing-related symptoms with severe hyperglycaemia, uncontrolled hypertension and refractory hypokalaemia, argued strongly for an ectopic Cushing's, as noted in the literature $[15,16]$. However, the diagnosis of pituitary ACTH hypersecretion was established with bilateral inferior petrosal sinus sampling, which is the gold-standard for etiologic diagnosis of ACTH-dependent Cushing's syndrome, as well as biopsy samples from the transsphenoidal pituitary surgery $[17,18]$.

\section{Conclusions}

We herein present a rare case of pulmonary nocardiosis associated with Cushing's disease. Nocardia spp. is an opportunistic pathogen causing well described disseminated or pleuropulmonary disease in the context of immunosuppression, and particularly in patients with exogenous hypercortisolaemia. It is very rarely reported as a cause of opportunistic infection in patients with endogenous Cushing's syndrome. However, clinicians should be aware of this complication, since the identification of the opportunistic infection could lead to the diagnosis of endogenous Cushing's syndrome. Moreover, due to this infections' high fatality rate, early correction of the causal factor of the immunodeficiency might give these patients a better chance of survival.

\section{References}

Ambrosioni J, Lew D, Garbino J. Nocardiosis: updated clinical review and experience at a tertiary center. Infection 2010;38:89-97.

Ott SR, Meier N, Kolditz M, et al. Pulmonary nocardiosis in Western Europe-Clinical evaluation of 43 patients and population-based estimates of hospitalization rates. International journal of infectious diseases. Int J Infect Dis 2019;81:140-8.

Chen J, Zhou H, Xu P, et al. Clinical and radiographic characteristics of pulmonary nocardiosis: clues to earlier diagnosis. PloS One 2014;9:e90724.
Haussaire D, Fournier PE, Djiguiba K, et al. Nocardiosis in the south of France over a 10-years period, 2004-2014. Int J Infect Dis 2017;57:13-20.

Takiguchi Y, Ishizaki S, Kobayashi T, et al. Pulmonary nocardiosis: A clinical analysis of 30 cases. Intern Med 2017;56:1485-90.

Wilson JW. Nocardiosis: updates and clinical overview. Mayo Clin Proc 2012;87:403-7.

Martinez R, Reyes S, Menendez R. Pulmonary nocardiosis: risk factors, clinical features, diagnosis and prognosis. Curr Opin Pulm Med 2008;14:219-27.

Filep JG, Delalandre A, Payette Y, Foldes-Filep E. Glucocorticoid receptor regulates expression of L-selectin and CD11/CD18 on human neutrophils. Circulation 1997;96:295-301.

Loriaux DL. Diagnosis and differential diagnosis of Cushing's syndrome. N Engl J Med 2017;376:1451-9.

Xu L, Xu Q, Yang M, et al. Nocardiosis in ectopic ACTH syndrome: A case report and review of 11 cases from the literature. Exp Ther Med 2016;12:3626-32.

Rizwan A, Sarfaraz A, Jabbar A, et al. Case report: nocardia infection associated with ectopic cushings. BMC Endocr Disord 2014;14:51.

Sutton BJ, Parks GE, Manavi CK, et al. Cushing's syndrome and nocardiosis associated with a pulmonary carcinoid tumor: report of a case and review of the literature. Diagn Cytopathol2011;39:359-62.

Chowdry RP, Bhimani C, Delgado MA, et al. Unusual suspects: pulmonary opportunistic infections masquerading as tumor metastasis in a patient with adrenocorticotropic hormone-producing pancreatic neuroendocrine cancer. Ther Adv Med Oncol 2012;4:295-300.

Lee SY, Oh YM, Lim CM, et al. A case of pulmonary nocardiosis in the patient with Cushing's disease. Tuberc Respir Dis 2004;57:61-5.

Ilias I, Torpy DJ, Pacak K, et al. Cushing's syndrome due to ectopic corticotropin secretion: twenty years' experience at the National Institutes of Health. J Clin Endocrinol Metab 2005;90:4955-62.

Torpy DJ, Mullen N, Ilias I, Nieman LK. Association of hypertension and hypokalemia with Cushing's syndrome caused by ectopic ACTH secretion: a series of 58 cases. Ann N Y Acad Sci 2002;970:134-44.

Deipolyi A, Bailin A, Hirsch JA, et al. Bilateral inferior petrosal sinus sampling: experience in 327 patients. J Neurointerv Surg 2017;9:196-9.

Bello CT, Gil I, Serra FA, Duarte JS. Acute severe Cushing syndrome: not always ectopic ACTH syndrome. AACE Clin Case Rep 2018;4:e45-e50. 